\title{
A Novel Variant of Tuberosclerosis: c.2458A>T in the 19th Exon
}

\author{
Fatih Kurt' ${ }^{1}$ Mustafa Doğan², Recep Eroz ${ }^{3}$ \\ ${ }^{1}$ Duzce University Faculty of Medicine, Pediatrics Clinic, Duzce, Turkey \\ 2 Malatya Turgut Ozal University Faculty of Medicine, Genetics Clinic, Malatya, Turkey \\ 3 Professor, Aksaray University Faculty of Medicine, Genetics Clinic, Duzce, Turkey
}

*Corresponding Author: Dr. Fatih Kurt, Department of Pediatrics, Duzce University Faculty of Medicine Turkey - 81000,

Phone: +90 5058380470, E-mail: fatihkurt 04@hotmail.com

\section{Abstract}

Rhabdomyomas are the most common congenital heart tumors. Rhabdomyomas are hamartomas of myocytes and benign heart tumors. In the postnatal period, it may be asymptomatic, or there may be findings such as murmur, arrhythmia, heart failure, and even hydrops. Echocardiography $(\mathrm{ECHO})$ is a very valuable method in its diagnosis. Rhabdomyomas can regress spontaneously. Rhabdomyoma of the heart is seen in $43-60 \%$ of tuberous sclerosis cases. Tuberous sclerosis is an autosomal dominant inherited neurocutaneous disease that causes the development of benign tumors called hamartoma in many systems such as brain, retina, kidneys, heart, skin and lungs. In this article, we wanted to contribute to the literature by presenting a new pathogenic c.2458A> T (p.Lys820Ter) variant that developed de novo in the TSC1 gene by genetic analysis of a patient with multiple cardiac rhabdomyomas.

Keywords: Tuberous Sclerosis, Cardiac Rhabdomyoma, TSC1 Gene.

\section{INTRODUCTION}

Rhabdomyomas are hamartomas of myocytes and the most common congenital heart tumors and can be diagnosed by ultrasonographic examinations after 32 weeks of gestation [1]. Tuberous sclerosis is an autosomal dominant inherited neurocutaneous disease that causes the development of hamartoma in many systems such as brain, retina, kidneys, heart, skin and lungs, which is seen in 1/6000-1/ 10000 live births [2]. Cardiac Rhabdomyomas are seen in $43-60 \%$ of tuberous sclerosis cases, therefore, rhabdomyoma cases should be evaluated in terms of tuberous sclerosis ${ }^{[3]}$.

\section{CASE REPORT}

The girl patient was born $39 \mathrm{w} 3 \mathrm{~d}, 3200 \mathrm{~g}$, by vaginal delivery. When she was 1 month old, she was brought to the Pediatrics Clinic. In the physical examination, the general condition is good, active, IR ++ / ++, no hypopigmented macules, no angiofibromas on the face, no periungal fibromas (Figure 1Bb). $\mathrm{S} 1+, \mathrm{S} 2+, 3 / 6$ systolic murmur was heard during cardiac examination, and he was referred to Pediatric Cardiology. Left ventricular systolic functions were found to be normal in echocardiography. Multiple rhabdomyoma of $10 \times 5 \mathrm{~mm}, 16 \times 9 \mathrm{~mm}$ and $12 \times 8 \mathrm{~mm}$ in size was found in the right ventricle (Figure $1 \mathrm{Ca}$ and $\mathrm{b}$ ). No arrhythmia was observed in the ECG and she was hemodynamically stable. Follow-up was planned, surgical intervention was not considered. Abdomen USG and urinary system USG were revealed normal. Retinal hamartoma was not detected on ophthalmological examination. The patient was referred to the Medical Genetics clinic to be evaluated for tuberous sclerosis. All exons and exon / intron junction regions encoding the TSC1 gene were sequenced in the patient by Sanger sequencing, and the $c .2458 \mathrm{~A}>\mathrm{T}$ variant was found as heterozygous state in the 19th exon (Figure 1A)(Table 1). As far as we know, this change has not been previously identified in any genetic database and was considered a novel variant. As a result of the segregation analysis performed in the family, it was determined that the variant developed de novo and was evaluated as a pathogenic variant according to ACMG guidelines (Figure 1Ba) [9]. The family was informed about possible convulsions and other risks. Genetic counseling was given to the family. The patient was referred to Pediatric Neurology Clinic for follow up of convulsions and Pediatric Cardiology Clinic for follow-up of rhabdomyomas. 

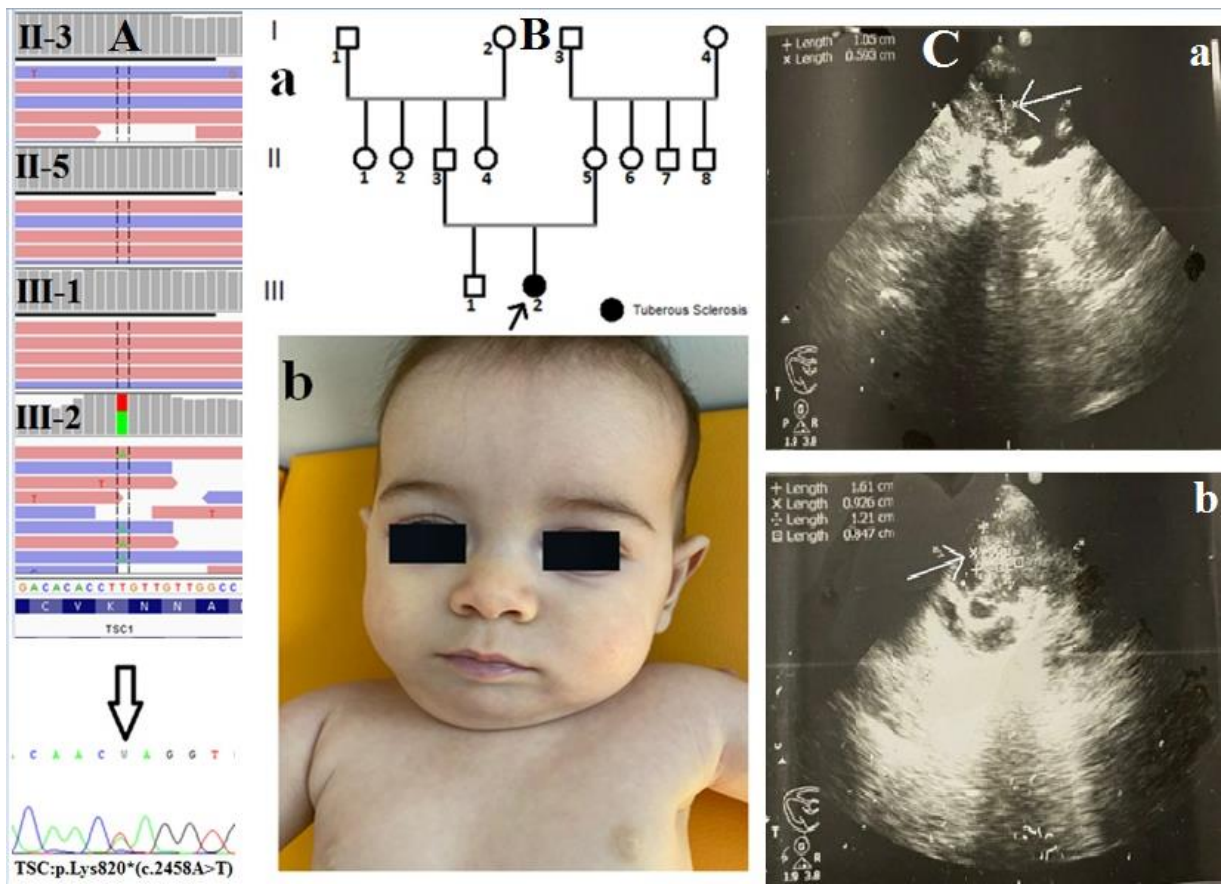

Figure 1: (A) Novel c.2458A>T p.(Lys820*) mutations in exon 19 of TSC1(NM_000368.5gene in probands(III-2). Normal sequence analysis appearance of TSC1 gene in II-3 (father), II-5(mother) and III-1(sibling). (B) Pedigree of the family. III-2 is proband and patient. I-1, I-2, I-3, I-4, II-1, II2, II-3, II-4, II-5, II-6, II-7, II-8 and III-1 are unaffected relatives. II-3 and II-4 are parents of our patient(a). The patient's facial appearance, No skin lesions were detected (b). (C) Echocardiography imaging findings of probands with rhabdomyoma ( $a$ and $b$ ).

Table 1: A Patient Who had a novel variant in TSC1 gene

\begin{tabular}{|l|l|}
\hline GENE & TSC1 \\
\hline Transcript ID & NM_000368.5 \\
\hline dbSNP & Novel \\
\hline Variant & c.2458A>T (p.Lys820*) \\
\hline Variant Location & Exon 19 \\
\hline Variant Type & Nonsense \\
\hline Mutation Taster & Disease causing \\
\hline Provean & Damaging \\
\hline SIFT & Damaging \\
\hline GnomAD (exomes) & Not found \\
\hline ClinVAR & Not found \\
\hline Conservation & conserved \\
\hline DANN score & 0.9966 \\
\hline GERP score & NR:5.23 RS:5.23 \\
\hline ACMG Classification & Pathogenic \\
\hline ACMG Pathogenity Criteria & PVS1,PM2,PP3 \\
\hline
\end{tabular}

\section{DISCUSSION}

Tuberous sclerosis disease was first described by DesireMagloire Bourneville as 'Bourneville disease' in 1880. It is a multisystemic, autosomal dominant disease that progresses with hamartomas in many organs such as the skin, central nervous system, kidney and lungs. Classical triad of Tuberosclerosis are seizures, mental retardation and cutaneous angiofibromas ${ }^{[4]}$. It is caused by the dysfunction of the TSC1 (9q34) and TSC2 (16p13) tumor suppressor genes. In these mutated cells, mTOR activation increases and it causes an increase in cell size and growth. $80 \%$ of the cases develop as a result of de novo mutation ${ }^{[5,6]}$.

Cardiac Rhabdomyomas are the most common congenital heart tumors. It has been reported to be detected with a frequency of approximately $0.027-0.08 \%$ in autopsy studies. Echocardiography $(\mathrm{ECHO})$ is a very valuable method in its diagnosis [1]. Rhabdomyomas may be asymptomatic in the postnatal period, or there may be findings such as murmur, arrhythmia, heart failure, and even hydrops. Most of cardiac rhabdomyomas tend to shrink spontaneously. Postpartum regression is observed in $70 \%$ up to 4 years and $17 \%$ after 4 years ${ }^{[7]}$. It has been reported that a tumor size of $20 \mathrm{~mm}$ and above is significant in terms of fetal dysrhythmia and hydrops. Surgical treatment is recommended for cases that cause mechanical stenosis in the heart or cause life-threatening arhythmias ${ }^{[8]}$.

\section{CONCLUSION}

In this article, we report a novel pathogenic c.2458A> T (p.Lys820Ter) variant that develops de novo in the TSC1 gene with the genetic analysis of a patient with multiple cardiac rhabdomyomas on his echocardiography and we want to contribute to the literature and remind again the association of cardiac rhabdomyoma with tuberosclerosis. 


\section{Conflict of Interest}

None declared.

\section{Financial Support}

None declared.

\section{REFERENCES}

1. Freedom RM, Lee KJ, MacDonald C, Taylor G. Selected Aspects of Cardiac Tumors in Infancy and Childhood. Pediatr Cardiol. 2000; 21:299-316.

2. Tsang SH, Sharma T. Tuberous Sclerosis. Adv Exp Med Biol. 2018; 1085:205-7.

3. Butany J, Nair V, Naseemuddin A, Nair GM, Catton C, Yau T. Cardiac Tumors: Diagnosis and Management. Lancet Oncol. 2005; 6:219-28.

4. Bourneville DM. Sclerose Tubereuse der Circonvolutions Cerebrales: Idiotie et Epilepsie Hemiplegique. Arch Neurol. 1880; 81-91.

5. Kwiatkowski DJ, Palmer MR, Jozwiak S, et al. Response to Everolimus is Seen in TSC-associated SEGAs and Angiomyolipomas Independent of Mutation Type and Site in TSC1 and TSC2. Eur J Hum Genet. 2015; 23(12):1665-72.

6. Li M, Zhou Y, Chen C, Yang T, Zhou S, Chen S, et al. Efficacy and Safety of mTOR Inhibitors (Rapamycin and its Analogues) for Tuberous Sclerosis Complex: a Meta-analysis. Orphanet J Rare Dis. 2019; 14(1):39.

7. Marx GR. Cardiac tumors. In: Emmanouilides GC, Riemenschneider TA, Allen HD, Gutgesell HP, et al. Heart Disease in infants, Children, and Adelescents. 5th ed. Baltimore, Md:Williams\& Wilkins. 1995; 1773-85.

8. Chen J, Wang J, Sun H, Gu X, Hao X, Fu Y, et al. Fetal Cardiac Tumor: Echocardiography, Clinical Outcome and Genetic Analysis in 53 Cases. Ultrasound Obstet Gynecol. 2019; 54(1):103-9.

9. Richards S, Aziz N, Bale S, Bick D, Das S, Gastier-Foster J, et al. Standards and Guidelines for the Interpretation of Sequence Variants: a Joint Consensus Recommendation of the American College of Medical Genetics and Genomics and the Association for Molecular Pathology. Genet Med. 2015; 17(5):405-24. 